\title{
El debate sobre la reforma del arbitraje como método de solución de controversias entre Estados e inversionistas extranjeros y las alternativas de un mecanismo de apelaciones y una corte multilateral de inversiones
}

\author{
Ricardo de Urioste*
}

\begin{abstract}
RESUMEN
Analiza el debate actual respecto a la necesidad de la reforma del arbitraje como el método preferido para resolver disputas entre Estados e inversionistas privados, específicamente en lo concerniente a las propuestas respecto a un mecanismo de apelaciones y una corte multilateral de inversiones. Presenta la novedad de traer a la discusión la teoría sobre regímenes internacionales a fin de subrayar la idea que el balance político subyacente se ha movido hacia un nivel sustancialmente menor de tolerancia del arbitraje ad hoc como un mecanismo eficiente de resolución de disputas inversionista-Estado. Pasa revista a los principales argumentos a favor y en contra de un mecanismo de apelaciones y concluye sugiriendo cómo es que las consideraciones precedentes resultan necesarias a fin de alcanzar una legítima definición de la posición del Perú respecto a esta cuestión en el debate internacional actual.
\end{abstract}

Palabras clave: derecho internacional de las inversiones, arbitraje internacional, régimen internacional, solución de controversias inversionista-Estado, mecanismo de apelaciones, corte multilateral de inversiones.

\footnotetext{
* Abogado y profesor ordinario de la Pontificia Universidad Católica del Perú. Posee el diploma Internacional de Relaciones Internacionales École Nationale d'Administration Publique (ENA)-París. Es magíster en Economía Política por la Internacional London School of Economics \& Political Science. LLM Universidad de Chicago. Es consultor, árbitro nacional e internacional, asesor externo del Perú y miembro del Foro Académico en las negociaciones de reforma del arbitraje inversionista-Estado de la Comisión de Naciones Unidas para el Derecho Mercantil Internacional (UNCITRAL). Correo electrónico: rdeurioste@pucp.edu.pe

(iD) https://orcid.org/0000-0002-8965-4638
} 
The debate on the reform of arbitration as investor-State dispute settlement method and the alternatives of an appellate mechanism and a multilateral investment court

\section{Abstract}

Analyzes the current debate regarding the need for reform of arbitration as the preferred method to solve disputes between States and private investors, more specifically regarding the proposals of an appellate mechanism and a multilateral investment court. It presents the novelty of bringing international regime theory into that discussion in order to highlight the idea that the underlying political balance has shifted towards substantially less tolerance of ad-hoc arbitration as an efficient mechanism to solve investor-State disputes. It reviews the main arguments in favor and against of an appellate mechanism and concludes by suggesting how these considerations are necessary in order to reach a legitimate definition of Peru's position regarding this issue in the current international debate.

Keywords: International investment law, international arbitration, international regime, investor-State dispute settlement, appellate mechanism, multilateral investment court.

\section{Introducción: planteamiento del ámbito del problema en este trabajo}

El debate relativo a la posibilidad y necesidad de reforma del arbitraje como método solución de controversias entre Estados e inversionistas extranjeros no es novedoso.

Ya en el año 2004 el Centro Internacional de Arreglo de Diferencias relativas a Inversiones (CIADI) sacó a la luz un documento titulado Possible Improvements for the Framework of ICSID Arbitration. Dicho documento incluso poseía un anexo en el que se perfilaban ciertas características técnicas que podría revestir un mecanismo de apelaciones en el seno del CIADI. Más aún, la literatura especializada que ha analizado la posibilidad e idoneidad de un sistema de apelaciones para el arbitraje que complementa o sustituya al arbitraje es de larga data (Knull y Rubins, 2000, p. 539; Holtzmann, 1995; Schwebel, 1995).

La discusión no se ha quedado en al ámbito académico y ya ha saltado a la arena de la práctica estatal y las negociaciones entre Estados. Así, el 13 de septiembre de 2017 se publicó la Recomendación de la Comisión Europea autorizando el inicio de negociaciones de una Convención relativa a un tribunal multilateral de inversiones. A partir de ese mismo año esta posibilidad de reforma es el objeto de extendidas negociaciones en el marco de la Comisión de Naciones Unidas para el Derecho Mercantil Internacional (UNCITRAL, por sus siglas en inglés).

La novedad del aporte de este trabajo no está, entonces, en el tema que constituye su objeto. Reside, más bien, en dos aspectos. 
El primero radica en pasar revista a buena parte de los diferentes argumentos que se han planteado a favor y en contra de la conveniencia de seguir confiando en un sistema de controversias que gira alrededor de un arbitraje de naturaleza ad hoc ${ }^{1}$, haciendo hincapié en la necesidad de no hacer dicho análisis en un vacío político, por demás artificial, sino con el trasfondo del consenso político internacional subyacente.

El segundo es anotar, al menos preliminarmente, las implicancias que este debate internacional pueda tener en el Perú, incluso más allá de la posición que asuma el Perú en los foros internacionales en los que los Estados se encuentran discutiendo este tema.

Bastaría como justificación de la pertinencia de un nuevo artículo sobre la reforma del arbitraje inversionista-Estado y el derecho aplicable en dichas controversias, la constatación de que, en la actualidad, se podría afirmar que esta reforma constituye el asunto más controvertido en el mundo del derecho internacional de las inversiones.

Adicionalmente, sin miedo a exagerar, también podría afirmarse que es el de mayores implicancias potenciales: la forma en que se decantará la práctica estatal a partir del resultado de este debate y las negociaciones en curso podría transformar radicalmente el sistema de solución de controversias inversionista-Estado tal y como lo conocemos en la actualidad.

Podría incluso significar la minimización y hasta la desaparición de las variantes actuales del arbitraje internacional institucional y ad hoc como mecanismos de solución de diferendos relativos a inversiones entre inversionistas privados y Estados soberanos.

Adicionalmente, resulta pertinente acotar que los cambios trascendentales que la reforma podría acarrear en el sistema internacional de protección y promoción de las inversiones no necesariamente se definirán en el largo plazo.

Como adelantáramos líneas arriba, existe un proceso de negociación de reforma en curso en el marco de la Comisión de Naciones Unidas para el Derecho Mercantil Internacional que en noviembre 2017 encargó a su Grupo de Trabajo III examinar si una reforma del sistema resulta deseable.

\footnotetext{
1 Para los efectos de esta discusión la referencia a la naturaleza ad hoc del arbitraje no hace referencia a la distinción, utilizada para efectos de clasificación de los arbitrajes, entre ad hoc e institucional. Se refiere más bien al elemento que caracteriza a todo arbitraje y que reside en la facultad de las partes de elegir a los árbitros que deberán resolver la controversia. Como se verá más adelante con mayor detalle, la crítica informada al sistema ha denunciado que en el caso del arbitraje inversionista-Estado, dicha característica ha desembocado en un sesgo pro-inversionista del sistema en general y, por lo menos, de un buen sector del número total, por demás reducido, de los árbitros que recurrentemente repiten como decisores de los casos. Todo ello redundaría en un desbalance de este sistema ad hoc en contra de los Estados.
} 
Este Grupo de Trabajo se reúne dos veces al año en sesiones regulares que tienen lugar, alternadamente, en las sedes de Naciones Unidas en Nueva York y Viena.

A partir de julio de 2019 el Perú es miembro pleno de la Comisión, después de 33 años de ausencia, por lo que se espera que desempeñe un rol activo en este debate y en las negociaciones.

Paralelamente, se encuentran en curso múltiples procesos de negociación de acuerdos internacionales de inversión tanto dentro como fuera del marco de tratados de libre comercio en los cuales los Estados participantes deberán asumir una posición respecto a la idoneidad de incluir un sistema de apelaciones o una corte multilateral. Por ejemplo, el Perú se encuentra en pleno proceso de negociación de un acuerdo de libre comercio que incluye un Capítulo de Inversiones y que lo involucra como parte de la Alianza del Pacífico en dicho proceso con los candidatos a Estados Asociados (Australia, Canadá, Nueva Zelandia y Singapur).

Adicionalmente, la necesidad de los Estados de tomar partido respecto a la presencia de un sistema de apelaciones o corte multilateral viene azuzada aún más porque ya han sido firmados algunos acuerdos, principalmente por la Unión Europea que no solo incluyen una corte permanente de apelaciones, sino que incluyen una corte permanente de primera instancia a fin de resolver este tipo de controversias. Así, por ejemplo, el Acuerdo Económico y Comercial Global entre Canadá y la Unión Europea (CETA, por sus siglas en inglés) y el Acuerdo de Libre Comercio entre la Unión Europea y Vietnam.

Por si ello fuera poco, como antecedentes existen múltiples capítulos de inversión en tratados de libre comercio vigentes por un período que se aproxima o sobrepasa ya la década y que contemplan negociaciones futuras para la puesta en marcha de un sistema de apelaciones.

Así, por ejemplo, el Perú incluyó provisiones al respeto en sus TLC con los EEUU, Canadá y México, pero una disposición similar respecto a la negociación futura de tal mecanismo se encuentra también en el Tratado de Libre Comercio entre los Estados Unidos, Centroamérica y República Dominicana (CAFTA) así como en los TLC de EEUU con Colombia y Ecuador.

No cabe duda entonces que tratar sobre este debate en la coyuntura actual resulta no solo conceptualmente estimulante sino tremendamente oportuno y necesario. 


\section{El problema de la legitimidad}

No cabe duda de que el mayor obstáculo que se le presenta hoy por hoy al arbitraje internacional de las inversiones es el de su legitimidad. Resulta evidente que cada vez le resulta más difícil justificar su lugar al interior de las negociaciones de acuerdos bilaterales de inversiones o de capítulos de tratados de libre comercio.

La realidad es que ningún país que negocia este tipo de instrumentos en la actualidad se embarca en una defensa irrestricta de las bondades del sistema. Generalmente, incluso aquellos países que proponen al arbitraje internacional como pieza fundamental de su modelo de negociación se ven obligados a aceptar la existencia de una serie de desequilibrios que han determinado la necesidad de incluir diversas disposiciones que apuntalen la posición defensiva de los Estados frente a las reclamaciones de inversionistas.

Así, por ejemplo, los Estados Unidos modificaron su modelo de negociaciones de acuerdos internacionales de inversión sustancialmente en el año 2004 y, posteriormente, en el año 2012 introdujeron algunos ajustes adicionales de menor envergadura. La modificación sustancial del año 2004 resultó claramente de la intención norteamericana de reforzar la capacidad defensiva del Estado a la luz de la reciente experiencia arbitral.

Sobre el particular afirma Johnson (2012):

This continued endorsement of the 2004 Model is notable because when that version was adopted, it departed in significant respects from the previous versions. Changes that were made in the 2004 version primarily (though not exclusively) included those that were made to be more, rather than less, protective of governments' regulatory authority and discretion. The modifications included those that:

o clarified and narrowed the definition of covered investments;

o changed and added language to explain and constrain the meaning of the "minimum standard of treatment" and expropriation obligations and closely guide arbitral tribunals' interpretations of those provisions;

o provided for exceptions to the agreements' prohibitions on performance requirements; o codified the stance adopted by the US government in other areas of international law and some earlier investment treaties by expressly declaring that the essential security exception is self-judging;

$\mathrm{o}$ added language to protect host-state authority to take measures relating to financial services; and

o modified some aspects of investor-state dispute settlement, such as adding a statute of limitations, and giving state parties to the treaty additional or clearer authority to determine issues of treaty interpretation and application that would be binding on investor-state tribunals. (pp. 1-2) 
En esta línea, la defensa de la inclusión del arbitraje en los acuerdos internacionales de inversión reposa hoy en día en argumentos tales como proponer que el arbitraje aún resulta útil, pero con la necesaria introducción de ciertos ajustes o modificaciones que lo mejoren o lo hagan aceptable al grueso de la opinión pública.

También es frecuente escuchar el argumento, menos conceptual y absolutamente contingente, basado en los resultados positivos obtenidos por tal o cual Estado en los arbitrajes en los que le ha tocado ser parte.

Menos convincentes aún resultan aquellos justificativos que se basan en la reticencia al cambio por simple inercia o temor a lo desconocido.

En el caso del Perú, se puede apreciar un fenómeno similar. Los típicos convenios bilaterales para la promoción y protección recíproca de inversiones que negociaba y suscribía nuestro país en la década de los noventa han sido sustituidos, esencialmente desde la negociación del Tratado de Libre Comercio con los Estados Unidos a partir del año 2004, por la estrategia de negociar capítulos de inversión que constituyen partes integrantes de tratados de libre comercio.

Dicha estrategia obedece indubitablemente a la intención de incluir en estos capítulos de inversión el tipo de provisiones de carácter defensivo que los Estados Unidos incluyeron en su modelo de 2004, pero también constituye una evidencia de la aceptación de la problemática que ya por esos años significaba el otorgamiento de las garantías que normalmente ofrecen los Estados a los inversionistas extranjeros, especialmente en lo que respecta al ofrecimiento de la cláusula arbitral que dispara el arbitraje internacional.

Esa nueva dificultad para justificar frente a la opinión pública la aceptación del arbitraje inversionista-Estado calza perfectamente con la nueva práctica de incluir capítulos de inversión en la matriz más amplia de los intercambios recíprocos que sustentan los tratados de libre comercio.

En otras palabras, la inclusión de estos capítulos de inversión (y del arbitraje internacional) al interior de los tratados de libre comercio revelaría la necesidad de hacer que la aceptación de dichas prerrogativas otorgadas al inversionista extranjero sean políticamente menos controversiales, apelando a las ganancias comerciales que justificarían la asunción del riesgo de los arbitrajes de inversión y que, evidentemente, no forman parte de la ecuación en un convenio de promoción y protección de inversiones por sí solo.

¿Cómo es que se llegó a esta atmósfera más crítica respecto a los acuerdos internacionales de inversión luego de que, a inicios de los años sesenta los promotores y pioneros de la creación del Centro Internacional de Arreglo de Diferencias Relativas 
a Inversiones (CIADI) propusieron al arbitraje como la ansiada respuesta del Banco Mundial a las controvertidas resoluciones de la Asamblea General de Naciones Unidas en materia de soberanía económica de los Estados y que no pintaban bien en materia de promoción del flujo internacional de capitales?

Resulta muy ilustrativa la descripción sobre la génesis del Convenio de Washington de 1965 sobre Arreglo de Diferencias Relativas a Inversiones entre Estados y Nacionales de Otros Estados que hace Lowenfeld (2009):

The initiative for the Convention came as a counterpoint to the debate that had gone for some ten years in various organs of the United Nations over the relation between host countries - i.e.developng countries - and foreign investors - i.e multinational corporations. A compromise Resolution on Permanent Sovereignty over Natural Resources had finally made it through the General Assembly, containing numerous recitals of sovereignty and self-determination and not much welcome to increased foreign investment $[\ldots]$.

At the World Bank, meanwhile, where the industrial states had greater voice and greater vote, a different perception was taking place. Neither the World Bank and its regional analogues, nor bilateral assistance programs such as the American "Alliance for Progress", could satisfy the needs for capital of the developing countries [...] But in the wake of decolonization in Africa and parts of Asia and take-overs of foreign investments throughout the Third World, potential investors would seek some protection before risking their capital and personnel in an often hostile environment. (pp. 48-49)

La pregunta respecto a este escepticismo contemporáneo en torno al arbitraje internacional resulta absolutamente imprescindible sobre todo después de constatar que ese convencimiento de los fundadores del sistema fue entusiastamente recogido en la década de los noventa del siglo pasado por aquellos Estados que, como el Perú, se habían afincado secularmente en la ribera tradicional de los países en desarrollo importadores netos de capitales y se protegían bajo el manto de la Cláusula Calvo.

La respuesta, lógicamente de naturaleza multivariable, pasa necesariamente por reconocer el protagonismo de una cuestión epistemológica y es que, indudablemente, el papel de los paradigmas resulta esencial en esta cuestión.

A mediados de la década de los noventa el mundo y, evidentemente, quienes tenían a su cargo el diseño de las políticas gubernamentales en materia de inversión extranjera abrazaron el paradigma neoliberal del Consenso de Washington en materia del libre flujo de capitales en el escenario internacional.

El efecto de este convencimiento en el diseño de las políticas gubernamentales que buscaban atraer inversión extranjera se encuentra en la actualidad bastante bien documentado. 
Basta la siguiente cita del profesor Vandevelde (2009) a fin de subrayar el rol que jugaron en dicho golpe de timón político el triunfo de la economía de mercado y la crisis de la atracción del tan necesitado capital extranjero en aquella época:

The Global Era also witnessed an explosion in the number of BITs. This explosion seems to have been rooted in two major causes. First was the victory of market ideology. The economic success of several Asian economies that had high rates of private investment and promoted the production of goods for export, relative to that of other developing countries that had pursued import substitution policies, demonstrated the constructive role that foreign investment and global integration could play in a developing economy. Specifically, during the period from 1965 to 1990, eight Asian economies grew at a rate three times that of Latin America and twenty-five times that of Sub-Saharan Africa. Further, the collapse of the Soviet bloc discredited the principal alternative to market capitalism as an economic policy.

Second was a loss of alternatives to foreign investment as a source of capital. The debt crisis of the 1980s had reduced the availability of private lending, which, by 1980, had accounted for half of all capital flows to developing countries. In addition, the massive federal deficits created during the Reagan administration had prompted extensive borrowing by the United States Government, which absorbed much of the available capital, further crowding developing countries out of the private market for credit. Reductions in developmental assistance at the behest of the Reagan administration during that same period had reduced the availability of public financing. (pp. 177-178)

Hoy en día la situación es sustancialmente distinta. No cabe duda alguna respecto a que el paradigma en esta materia ha evolucionado nuevamente, especialmente desde la crisis financiera del año 2008.

Esta evolución en el paradigma respecto a la firma de acuerdos internacionales de inversión manda que cualquier mecanismo que prometa un aumento en el flujo de inversión extranjera ya no sea abrazado en forma ciega o basándose únicamente en los pergaminos de un efecto dominó de aplicación generalizada de hace más de veinte años. Hoy en día todo apunta más bien a la necesidad de un previo análisis integral respecto a las ventajas y desventajas que presentaría su adopción.

En este contexto no deberían sorprender entonces las severas críticas que han mantenido ciertos sectores de la sociedad civil, sobre todo en algunos países desarrollados, en contra de los acuerdos internacionales de inversión en general, pero sobre todo en contra del arbitraje inversionista-Estado en particular.

No es este el momento para hacer un análisis exhaustivo sobre esta crítica que acompaña y mantiene una relación simbiótica con la visión que mantiene una postura marcadamente contraria a la globalización. Bastará decir sobre este punto que gran parte de esta crítica se encuentra en realidad altamente ideologizada y por ello resulta 
en ocasiones destemplada y no presenta argumentos concretos más allá de su disgusto generalizado.

El propósito que anima a esta versión extrema es desterrar a como de lugar al arbitraje inversionista-Estado sin presentar un discurso informado. No sorprende, por tanto, el radicalismo y la exageración en sus conclusiones que no toman en cuenta los argumentos respecto a las ventajas que puede aportar la presencia de inversión extranjera en una economía, más allá de la imperiosa necesidad de contar con ella en países como el Perú en los que el nivel de ahorro interno simplemente resulta insuficiente para arribar a la meta del desarrollo económico. Suscintamente, estos argumentos son expresados por Mankiw (2012):

Sin embargo, la inversión del extranjero es una forma para que un país crezca. Aun cuando algunos de los beneficios de esta inversión fluyen de regreso a los inversionistas extranjeros, esta inversión sí incrementa las acciones de capital de la economía, lo que conduce a una mayor productividad y a salarios más altos. Además, la inversión del extranjero es una forma para que los países pobres aprendan las tecnologías más modernas que se desarrollan y se utilizan en países más ricos. Por estas razones, muchos economistas que asesoran a los gobiernos en países menos desarrollados recomiendan políticas que alientan la inversión del extranjero. (p. 543)

No obstante, sin dejar de desconocer dicha realidad respecto a un sector crítico que en realidad no aporta a la discusión constructiva sobre el tema, tampoco puede caerse en el extremo de considerar que toda crítica al sistema actual resulta a priori fuera de lugar.

Adicionalmente, deberá reconocerse también que incluso en caso que la crítica sea infundada o exagerada, cabe la posibilidad que ella anticipe un consenso social y una realidad política que podría haber declarado su intolerancia con la versión actual del sistema arbitraje inversionista-Estado.

Podría ser que dicha realidad social y política subyacente haya ya sentenciado la necesidad de al menos una reforma sustancial de dicho sistema arbitral y frente a ello sería fútil anteponer el recurso académico de insistir en argumentos técnicos que pretendan salvar a dicho sistema de manera trasnochada.

Si fuera así el arbitraje inversionista-Estado no podría aferrarse a su marcada naturaleza ad hoc tal y como existe en la actualidad, sino que deberá inexorablemente adaptarse a la nueva realidad política que constituye no solo su contexto sino la fuente de su legitimidad.

Un fuerte indicio de dicho cambio se aprecia en lo que ha sucedido a este respecto en la Unión Europea. En diciembre de 2016 la Comisión Europea recibió el mandato de negociar acuerdos de inversión que incluyan una corte permanente de inversiones. 
Dicho mandato se basó en una consulta popular y dicho proceso ha sido bien recogido por José Manuel Álvarez (2018):

Legitimacy concerns regarding the ISDS system, such as lack of coherence, predictability, and biased arbitrators, have been at the center of debates since cases were recorded under the Argentinian crisis in the early 2000s [...].

In 2014, during ongoing trade and investment negotiations between the EU and the United States, the European Commission (EC) launched a public consultation on international investment and the ISDS. The results of the consultation and parliamentary debates, which considered criticisms from academia, human rights, consumer associations, and environmental organizations, gave the EU the tools to say that ISDS transformation was needed. The system was perceived as illegitimate, partial and opaque. (pp. 2766-2767)

Posteriormente, el Tribunal de Justicia de la Unión Europea (30 de abril de 2019) ha ratificado que dicha corte multilateral de inversiones sí cumpliría con las garantías mínimas de un sistema de justicia conforme a la legislación comunitaria, lo cual puede ser interpretado, a contrario sensu, en detrimento del imperante sistema arbitral ad hoc en el sentido que este último no cumpliría con estas garantías mínimas de un verdadero sistema de justicia de conformidad con el estándar europeo.

Finalmente a fin de redondear el argumento que entiende que el contexto económico y político mundial evidencia un cambio en la mentalidad respecto a la idoneidad del arbitraje ad hoc tal como se ha venido aplicando como parte necesariamente integrante de un esquema exitoso de atracción de inversión extranjera, podemos recurrir a una voz tan desprovista de sospecha de sesgo antiarbitraje como la de Jan Paulsson, conspicuo y tradicional promotor del arbitraje como mecanismo de solución de controversias. Paulsson (2014) admite el problema de legitimidad que debe enfrentar en la actualidad el arbitraje y debe recurrir a argumentos extremos como la prevención del auge del totalitarismo a fin de hacerle frente a la crítica proveniente desde la perspectiva de la intromisión injustificada en perjuicio de políticas públicas razonables:

True enough, there is little new under the sun, and one should not exaggerate the novelty of the process being observed. The proposition that arbitral determinations may potentially conflict with the policies of public authorities has been examined in the past. But not all such policies are to be given automatic credence. Come to think of it, why is it that totalitarian regime abhor arbitration? For decades, Franco's Spain and Salazar's Portugal maintained the Iberian Peninsula as a veritable backwater for arbitration, even as Western Europe was moving steadily toward the recognition of arbitral autonomy. (p. vii) 


\section{El juego de los adivinos y las bolas de cristal: argumentos a favor y en contra del mecanismo de apelaciones y cortes de inversiones}

En esta sección pasaremos revista a algunos de los argumentos más importantes planteados a favor y en contra de la instauración de un sistema de apelaciones o una corte multilateral de inversiones, esta última en la línea de la propuesta de la Unión Europea puesta bajo consideración en el marco de las negociaciones en UNCITRAL.

Si bien la opción de un sistema de apelaciones y aquella relativa a una corte multilateral no resultan idénticas, se aproximan en su percepción común respecto a lo que ambas entienden como los dos grandes problemas derivados de la naturaleza ad hoc del sistema actual de arbitrajes inversionista-Estado: la falta de uniformidad y coherencia y resultante incertidumbre de que adolece el conjunto de las decisiones arbitrales y los efectos negativos sobre los requerimientos de independencia e imparcialidad que deberían rigurosamente caracterizar la actividad de los árbitros.

Sería imposible, dadas las limitaciones de extensión del presente trabajo, considerar todas las variables que resultarían relevantes para construir opciones detalladas de reforma del arbitraje inversionista-Estado. Menos aún alcanzaríamos aquí a agotar la consideración de dichas opciones de reforma resultantes de la mencionada multiplicidad de variables, no solo por su amplio número, sino porque además muchas de esas opciones no resultan excluyentes entre sí y pueden compartir características, por lo que dicho estudio detallado se multiplicaría más allá de lo aconsejable en esta oportunidad ${ }^{2}$. En el ánimo de simplificar el problema pero a la vez subrayando los elementos esenciales de este debate en marcha, dedicamos las dos siguientes secciones a ilustrar la contraposición existente entre los principales argumentos a favor y en contra de la instauración de mecanismos tales como un sistema de apelaciones o una corte multilateral de inversiones.

\section{Argumentos en contra}

\subsection{El carácter fragmentado del sistema del derecho internacional de las inversiones}

Para nadie es un secreto que el sistema del arbitraje internacional de inversiones reviste un marcado carácter atomizado. No existe un acuerdo multilateral de inversiones que

\footnotetext{
2 Por ejemplo, la opción de una instancia de apelaciones no necesariamente tendría que asumir el carácter de instancia permanente que sí resulta consustancial a la alternativa de una corte multilateral. La alternativa de la instancia de apelaciones podría asumir, en tal caso, la forma de un conjunto cerrado o roster de especialistas elegidos por los propios Estados partícipes del sistema y entre los cuales se debería elegir (ya sea por las partes o por una instancia de designación) a fin de integrar el colegiado encargado de las apelaciones para cada caso concreto.
} 
centralice en un único instrumento internacional el derecho aplicable en materia de tratamiento a la inversión y a los inversionistas extranjeros.

Dicha situación contrasta particularmente con la situación existente en materia de comercio internacional, donde los Estados miembros de la Organización Mundial de Comercio han logrado crear y colocar bajo su administración un cuerpo centralizado y unificado de normas que constituyen el régimen legal del comercio internacional aplicable entre los Estados participantes, que llegan al significativo número de 164.

Conforme a este argumento ese régimen legal único sería precisamente el basamento que ha posibilitado y además se retroalimentaría de la actividad de un Órgano de Apelaciones que solo sería posible en dicho contexto de aplicación de un solo cuerpo legal.

A diferencia del derecho de la Organización Mundial de Comercio, el derecho internacional de las inversiones se caracteriza, como ya hemos anticipado líneas arriba, más bien por una multiplicidad de acuerdos mayormente bilaterales distintos, cada uno producto y prisionero a la vez de la realidad particular a la que debe responder.

Siempre en esta línea de razonamiento, dicha realidad fragmentada haría imposible cualquier intento de unificación o armonización de decisiones de arbitrales tribunales absolutamente independientes, por la vía de un tribunal de apelaciones.

En esta línea podemos citar el razonamiento de Luis González García (2015), formulado en torno a la inconveniencia de una corte multilateral, pero que él mismo extiende al supuesto de un sistema de apelaciones:

An international investment court would be most appropriate if there were a single body of law, such as ITLOS and the ECHR. With more than 3,000 IIAs in place and more than 514 treaty-based cases, doubts remain as to how an investment court that would have jurisdiction over a considerable number of legal texts with different wording could sort out the ambiguity, confusion and contradiction in investment treaty arbitration. (pp. 431-432)

Desde esta perspectiva, la creación de un tribunal de apelaciones simplemente no calzaría con la naturaleza esencialmente independiente de los tribunales arbitrales prevista en los acuerdos internacionales de inversión.

\subsection{No asegura consistencia o podría desembocar en consistencia que no resulte favorable para los Estados}

Este argumento se alinea con el tipo de razonamientos que se fundan en el dicho «el remedio podría ser peor que la enfermedad». 
En efecto, la idea fundamental detrás de esta señal de alarma es la de prevenir que apostar por un mecanismo de apelaciones o una corte multilateral constituiría una apuesta muy riesgosa e incierta porque no existiría ningún indicio, ni mucho menos aún una garantía de que dichos mecanismos desemboquen en una línea uniforme de decisiones, análoga a una suerte de «jurisprudencia arbitral» que favorezca a los intereses de los Estados en sus controversias con inversionistas privados.

Este razonamiento podría intentar buscar apoyo adicional precisamente en la diversidad de las decisiones de los laudos arbitrales que algunos pretenden criticar.

En este sentido resulta ilustrativa la posición del experimentado abogado Barton Legum (2015), asiduo participante en arbitrajes de inversión:

The wrong sort of appellate mechanism could do irreparable damage to international investment law. Consider, for example, an appellate mechanism that viewed itself as a sort of constitutional court with a broad mandate to protect investors, and which ruled consistently in favor of the investor position in every case to come before it. As another example, consider an appellate mechanism with a majority of members appointed by developing States under a one-country/one-vote approach, which consistently sided with the State in every case brought before it. Either one of these would be a disaster for international investment law and a significant step backward from the current system. The stakes, I noted, were sufficiently high that an appellate mechanism could be justified only if a compelling need could be shown for it. (pp. 438-439)

El corolario de esta postura sería, entonces, que si partimos de la premisa que la diversidad o falta de uniformidad en las decisiones de los tribunales arbitrales en materia de inversiones no se desprende de excesos procesales, extralimitaciones manifiestas o motivaciones insuficientes, sino de legítimas interpretaciones de árbitros perfectamente capaces, entonces no resultaría lógico esperar que el solo hecho de instaurar un tribunal más o menos permanente o un mecanismo de revisión modifique esa diversidad en los laudos de manera mágica, o perversa en el peor de los casos.

Todo lo contrario, existiría el gran riesgo que, buscando uniformidad y certidumbre, se termine por sesgar la naturaleza del tribunal ya sea en favor de los inversionistas o del Estado, resultando en ambos casos en un despropósito que derrotaría el objetivo de concretar un sistema eficiente e imparcial.

\subsection{Mayores costos y duración}

Este argumento pretende exponer una correlación que, al menos de primera intención, parecería evidente. Un sistema de apelaciones e incluso en mayor medida una corte multilateral, acarrearían mayores costos para los usuarios del sistema, incluso para los Estados intervinientes. 
Ello tanto por la vía directa de tener que sufragar la implementación y la manutención de tales instancias, como por la vía indirecta de la mayor duración de los procesos producto de la instauración de cualquier tipo de mecanismo que pueda revisar el examen de los hechos y derecho ${ }^{3}$ efectuado previamente por la instancia anterior o inferior.

\subsection{Aumenta el riesgo de una politización extendida}

Para un sector de la crítica la creación de una instancia de apelaciones, al menos en la versión que incluye elementos institucionales más o menos permanentes derrotaría precisamente una de las razones de ser esenciales y una motivación determinante detrás de la institución del arbitraje como principal método de solución de controversias entre Estados e inversionistas.

Siempre conforme a esta manera de ver las cosas, una de las grandes ventajas de esta importación del mecanismo del arbitraje al mundo del derecho internacional público sería la despolitización de la solución de las controversias inversionistaEstado al aislar a estas controversias de la intervención o presiones del Estado de la nacionalidad del inversionista.

En este orden de ideas la idea original de recurrir al arbitraje como mecanismo de solución de controversias entre privados y Estados soberanos respondía a la intención de calmar las ansiedades de países en desarrollo que por aquella época mantenían una tremenda desconfianza y recelo frente al poder y los intereses de países desarrollados que en muchos casos coincidían con las antiguas potencias coloniales de las que se acababan de independizar.

Resumiendo, entonces, este argumento sostiene que el mecanismo del arbitraje permite la despolitización o al menos minimiza la politización y monta el escenario idóneo para hacer viable una solución de orden técnico-jurídico a las controversias entre inversionistas y Estados receptores de dicha inversión, en la medida que minimiza o, aún más optimistamente, alivia las tribulaciones de orden político de un Estado que se asume es el más débil en la balanza política de los dos (o más) Estados interesados en la controversia.

\footnotetext{
3 La propuesta de la Corte Multilateral de Inversiones de la Unión Europea no ha definido aún si su ámbito de aplicación se extendería únicamente a cuestiones de derecho o abarcaría también el examen de la evaluación de los hechos efectuada por el tribunal de primera instancia que su propuesta también prevé. En tratados de libre comercio concluidos con Canadá y Vietnam, por ejemplo, la UE logró incluir una instancia de apelaciones que se extiende a cuestiones de derecho y manifiestos errores manifiestos en la apreciación de los hechos. Algunos países, como es el caso de la Argentina, han expresado su preferencia porque la instancia de revisión incluya tanto cuestiones de derecho como cuestiones de hecho sustanciales.
} 
Incluso si se tratara de Estados con cuotas de poder equiparables, la promesa de la esterilización política ofrecida permitiría arribar a una solución de índole estricta o mayormente jurídica sin comprometer las relaciones políticas entre los Estados involucrados o concernidos.

\subsection{La politización extendida podría hacer que el sistema termine en el estancamiento que caracteriza, por ejemplo, actualmente a la OMC}

Este argumento se encuentra estrechamente ligado con el anterior ya que se encuentra anclado en la pretendida constatación de los efectos de la contraposición de intereses y el desbalance de poder en las relaciones internacionales.

La idea principal es que los Estados más poderosos de hecho aprovechan la posibilidad que tienen de diseñar e implementar reglas que los favorezcan en el ámbito institucional internacional y ello se vería reflejado en la composición y en las reglas de funcionamiento del tribunal permanente de apelaciones o de una corte multilateral (poder estructural).

En este sentido, José Manuel Álvarez apunta al riesgo de repetir el resultado que él encuentra en detrimento de los países en desarrollo y que fuera orquestado por los países europeos a su favor en las experiencias de las Conferencias de La Haya y de París de 1907 y 1919, respectivamente:

Second, this Essay aims to show that the current process for implementing a MIC echoes prior European behavior during the Hague and Paris Conventions. This Essay compares political and theoretical discussions that took place during the Hague's Second Conference of 1907, when the Permanent Court of Arbitral Justice (PCAJ) was established, and in the Paris Conference of 1919 when the establishment of a Permanent Court of International Justice (PCIJ) was discussed. These two projects sought to solve Europe's persistent war problems. In both instances, European powers used their influence to multilateralize their own interests when sketching the proposals to establish a world court, without considering the interests of SMEs, which were not included in the text of the Conventions. The current MIC negotiations could repeat the same history, evidenced by the EU's behavior in other treaties and organizations, such as UNCITRAL, EU-Vietnam FTA, and the CETA blueprint. (Álvarez, 2018, pp. 2771-2772)

Este argumento pretendería apoyarse adicionalmente en evidencia empírica reciente que señala en la dirección de la situación actual del impasse político en el Órgano de Apelaciones de la OMC como el espejo en que se debería mirar la propuesta análoga en materia de inversiones. 


\subsection{Traería un desbalance a favor de los Estados que daría al traste justamente con el propósito de atraer capital extranjero}

Esta tesis parte de la identificación del propósito del régimen internacional actual en materia de inversión extranjera con la atracción de dicho flujo de capital proveniente del exterior.

Conforme a esta idea, la inclusión del arbitraje como mecanismo de solución de controversias entre inversionista y Estado responde precisamente a dicho rol promotor de las políticas nacionales en materia de inversión extranjera que buscan recibir dicho capital a fin de suplir o coadyuvar al nivel de ahorro interno.

En esta línea si se incluye un elemento distorsionador o, en el peor de los casos, si se elimina el arbitraje como característica esencial pro-inversionista en ese diseńo de atracción de capitales, se estaría derrotando justamente su razón de ser.

\subsection{Desnaturalizaría a un sistema que ha funcionado bien y que ha probado su valía en la práctica (incompatibilidad con el sistema CIADI y otras instituciones parte del sistema actual)}

Nuevamente, este argumento podría resumirse en otro dicho proveniente del idioma inglés y que se deja traducir como «no requiere arreglarse si no está roto».

La idea básica aquí es que el sistema de arbitraje como solución de controversias inversionista-Estado ha probado su valor desde su incepción en la década de 1960, aunque más bien debería remontarse este récord de eficiencia a la década de los setenta a fines de la cual se emitió su primer laudo (CIADI, 29 de agosto de 1977) o incluso más acertadamente a la década de 1990 en la que el sistema experimentó su verdadero auge.

¿Por qué entonces arriesgar un sistema que ha probado su efectividad y sustituirlo por un salto de fe en favor de otro que conllevaría la anulación del anterior a pesar del éxito que ha tenido en la práctica?

No cabe duda que dicho éxito ha ido de la mano del desempeño también exitoso del CIADI, como foro institucional preferido por los actores del sistema hasta volverse en figura icónica y, a veces, coloquialmente, hasta en sinónimo del arbitraje de inversión.

Dicho éxito ha generado un argumento derivado que apoya la recomendación de no embarcarse en la incierta expedición de la sustitución del arbitraje. Esta idea encuentra su mayor fortaleza como contrapeso a la propuesta de una corte multilateral de inversiones, así como a la de una instancia de apelaciones. 
Ahí radica la sustancia de esta argumentación en favor del CIADI y el desincentivo que ello debería significar para alejarse de la naturaleza ad hoc del arbitraje inversionista-Estado.

¿Cómo así? El razonamiento se bifurca en dos planos: uno relativo a la ejecución de un laudo CIADI al interior del Estado inmerso en la controversia o de cualquier otro Estado miembro del Convenio CIADI, y el otro plano, relativo a la ejecución de un laudo CIADI en los territorios de Estados que no son miembros.

En lo que respecta al Estado que es parte en la controversia con el inversionista, el marco CIADI cuenta con el artículo 54 (1), fundamental en materia de ejecución de laudos:

Todo Estado Contratante reconocerá al laudo dictado conforme a este Convenio carácter obligatorio y hará ejecutar dentro de sus territorios las obligaciones pecuniarias impuestas por el laudo como si se tratare de una sentencia firme dictada por un tribunal existente en dicho Estado. (el resaltado es nuestro)

¿Una decisión o sentencia emitida por un mecanismo de apelaciones cumpliría con el requisito esencial de conformidad con el Convenio CIADI?

Esta postura entiende que no, toda vez que el marco CIADI tiene como piedra angular la finalidad de los laudos emitidos y únicamente reconoce el recurso de anulación previsto en su artículo 52. El artículo 53 del Convenio sería inflexible al respecto:

El laudo será obligatorio para las partes y no podrá ser objeto de apelación ni de cualquier otro recurso, excepto en los casos previstos en este Convenio.

La incompatibilidad sería, por tanto, insalvable y se requerirá la unanimidad a que se refiere el artículo 66 del Convenio CIADI para introducir modificaciones.

Exactamente la misma situación se configura en el caso de ejecución de laudos CIADI en el resto de Estados miembros del Convenio, dada la amplitud de la disposición del artículo 54.

En lo que concierne a la ejecución de un laudo CIADI en Estados que no son miembros del Convenio resulta esencial la complementariedad y asistencia que brinda la Convención de Nueva York de 1958 sobre el Reconocimiento y Ejecución de las Sentencias Arbitrales Extranjeras.

El artículo 1 de la Convención de Nueva York define su ámbito de aplicación respecto a la naturaleza de las decisiones a las que ampara:

1. La presente Convención se aplicará al reconocimiento y la ejecución de las sentencias arbitrales dictadas en el territorio de un Estado distinto de aquel en 
que se pide el reconocimiento y la ejecución de dichas sentencias, y que tengan su origen en diferencias entre personas naturales o jurídicas [...].

2. La expresión «sentencia arbitral» no solo comprenderá las sentencias dictadas por los árbitros nombrados para casos determinados, sino también las sentencias dictadas por los órganos arbitrales permanentes a los que las partes se hayan sometido. (el resaltado es nuestro)

¿Las decisiones emitidas por una instancia de apelaciones o una corte multilateral de inversiones calificarían dentro del concepto de sentencias dictadas por los órganos arbitrales permanentes?

La postura que apoya el carácter ad hoc del arbitraje de inversiones mantiene serias dudas respecto a dicha calificación debido a que la decisión emitida por una instancia permanente de segunda instancia resultaría conceptualmente muy distinta a un laudo arbitral. Adicionalmente, señala que el legítimo carácter de dicha duda llevaría a que la cuestión tenga que ser ventilada y decidida frente a cortes nacionales las que en última instancia serían las llamadas a decidir sobre el amparo de la Convención de Nueva York en cada caso concreto. Ello determinaría un nivel de contingencia e incertidumbre que el régimen actual de laudos arbitrales logra superar.

\section{Argumentos a favor}

\subsection{Una instancia de apelaciones o una corte multilateral son posibles en el contexto de la diversidad de acuerdos internacionales de inversión}

Conforme a esta interpretación si bien el derecho aplicable a las controversias de inversión deriva de la amplia diversidad de un universo atomizado de más de tres mil acuerdos de inversión, ello no constituye un verdadero impedimento conceptual para la vía de la búsqueda de uniformidad a través de un órgano de apelaciones o una corte multilateral.

Después de todo, si bien dicha diversidad es una característica distintiva e innegable del régimen internacional de acuerdos de inversión el funcionamiento de un órgano de apelaciones o corte multilateral no presupone una absoluta identidad de las reglas de fondo o procedimentales que se aplican en las decisiones de primera instancia.

Como anotáramos líneas arriba es cierto que los distintos tratados de inversión son fuentes de derecho absolutamente independientes unas de otras. No obstante, muchas de las redacciones se repiten o son muy similares y otro elemento importante de uniformidad dentro de la diversidad es que los supuestos que pretenden regular son los mismos. 
Incluso más allá de coincidencias en la redacción, las categorías conceptuales básicas son comunes a prácticamente todos los acuerdos de inversión, tales como trato justo y equitativo, estándar mínimo de trato, cláusula de la nación más favorecida, trato nacional, requisitos de compensación pronta, adecuada y efectiva en materia expropiatoria, perfilamiento de la expropiación indirecta ${ }^{4}$, entre otras.

Incluso existen problemas emblemáticos que también son comunes o podrían presentarse en la aplicación de prácticamente todos los acuerdos existentes. De hecho, se han presentado cuestiones que han sido llevadas recurrentemente ante tribunales arbitrales que han debido enfrentarse esencialmente al mismo problema sin necesidad de que las distintas controversias surjan del mismo acuerdo de inversión. Así por ejemplo, la aplicación de la cláusula de la nación más favorecida a temas procesales (cuestión Maffezini), extensión del ámbito de protección del trato justo y equitativo y relación con el estándar mínimo de trato, posibilidad de accionistas de presentar reclamaciones por dańos sufridos en cabeza de la sociedad en la que participan, interpretación que justifica la protección de la cláusula paraguas, aplicación de la defensa del estado de necesidad como causal eximente de responsabilidad, entre las más saltantes.

Todos ellos constituyen denominadores comunes que justificarían la presencia de un mecanismo unificador del conjunto de decisiones arbitrales que otorgue, dentro de lo posible, un nivel de certidumbre que, sin duda, elevaría el nivel de legitimidad del sistema.

Este último punto es crucial en esta argumentación. Al respecto, resulta muy ilustrativo le señalado por Bottini (2015):

Secondly, it has been contended that "it is doubtful that an appeals facility would achieve the goal of harmonization of investment law," not least because, inter alia, "[m]ost investment treaties are bilateral, they currently number approximately three thousand, and their terms are not identical." Further, in accordance with general principles, it has been observed that even facially similar treaty provisions may nonetheless have to be interpreted in a different way. Indeed, this diversity in the applicable law limits, to some extent, the lessons that can be drawn from the (generally regarded) successful experience of the WTO's Appellate Body. But here again, this point should

\footnotetext{
${ }^{4}$ El caso de la expropiación indirecta es especialmente interesante y fértil para criterios unificadores a ser decantados por una instancia unificadora porque al ser su examen eminentemente casuístico, básicamente lo que existe actualmente es una ausencia de normas generales relativas a su identificación. Por ejemplo, en los convenios bilaterales de promoción y protección recíproca de inversiones que constituyen la primera generación de acuerdos firmados por el Perú no existe referencia alguna al término. En los capítulos de inversión en tratados de libre comercio lo que existe es un anexo que brinda algunos lineamientos para los árbitros al enfrentarse a un caso de expropiación indirecta, lineamientos que mayormente son una repetición de algunos enunciados generales de la «jurisprudencia» arbitral.
} 
not be overstated. Any investment arbitration practitioner knows that, despite the fact that arbitrations generally involve the application of many different treaties, the parties invoke roughly the same cases in support of their positions. Moreover, the referred-to main inconsistencies are generally reflected in two (or in any event very few) basic approaches to the issues, notwithstanding the different formulations of the standards of protection found in international investment agreements. An appeals mechanism that brings more consistency to investment arbitration at the level of general principles would probably contribute significantly to consistency, notwithstanding the more than 3000 investment agreements currently in force. (pp. 468-469)

Hemos señalado líneas arriba que uno de los argumentos en contra de una instancia de apelaciones o corte multilateral apunta a que los Estados han sobredimensionado esta crítica respecto a la falta de homogeneidad porque en realidad las interpretaciones de los tribunales arbitrales ya guardan una cierta uniformidad y las interpretaciones antojadizas son la excepción, no la regla.

Frente a dicho argumento, los partidarios de la harmonización podrían fácilmente retrucar que si dicha uniformidad realmente existiera, entonces ello simplificaría muchísimo la tarea del tribunal de apelaciones, quien solo debería recoger ese consenso supuestamente imperante y vigilar que los laudos a futuro no se salgan del redil, pero que habría un valor agregado importante.

Dicho añadido es que la preocupación de los Estados de incluir un mecanismo que asegure la captura de cualquier exceso por parte de los tribunales resultaría perfectamente legítimo: constituiría una declaración por parte de los Estados de que simplemente no están dispuestos a correr el riesgo de interpretaciones idiosincrásicas de los árbitros, a lo Mafezzini, independientemente de la baja probabilidad. En dicho razonamiento simplemente el riesgo de una decisión antojadiza o radical por menor que sea resulta ahora un riesgo intolerable.

\subsection{Argumento en favor de la consistencia y coherencia en el conjunto de decisiones arbitrales}

Este argumento se encuentra estrechamente interrelacionado con el anterior. Parte de la constatación de que no es necesario pasar revista a un conjunto particularmente significativo de laudos arbitrales a fin de arribar a la conclusión de que la naturaleza ad hoc del sistema conlleva inherentemente el riesgo de incoherencia y dispersión en el sentido de las decisiones.

Ya hemos visto cómo el argumento en contra basado en la multiplicidad de acuerdos subyacentes no parece tener asidero. Sobre este punto cabría añadir que el argumento basado en la multiplicidad desconoce las analogías que muestran que tal instancia es posible dentro de la diversidad normativa. Así, por ejemplo, en el derecho contrac- 
tual nadie niega dicha posibilidad en un sistema que incluye la convivencia de reglas generales más allá de la diversidad de las disposiciones particulares negociadas en cada contrato.

Hemos visto también que frente a esta situación los Estados pueden legítimamente decidir minimizar el riesgo de un laudo descarrilado que consagre una interpretación antojadiza en favor del inversionista. De hecho, este parece ser el estado actual de la cuestión.

A fin de ganar y darle esa necesaria dosis de consistencia al sistema, parece lógica la opción de un mecanismo de apelaciones o corte multilateral.

Este argumento se encuentra muy ilustrativamente resumido por Howard en un artículo en el que añade la variable respecto a la utilidad que aportaría un mayor nivel de certidumbre en la solución de controversias a un sistema que pretende también cumplir un rol de promoción a los flujos de inversión extranjera:

Inconsistent decisions by arbitral tribunals threaten the legitimacy of investment arbitration. The necessity of consistent and coherent decisions is arguably the most persuasive critique of international investment arbitration and the primary reason for instituting a World Investment Court. Inconsistency provides a foundation for allegations of unfairness, in addition to creating a lack of predictability and reliability in the investment arbitral system. With the increase of investment disputes, there has been an increase of inconsistent arbitral decisions, where one tribunal interprets a provision or provides a judgment that conflicts with another tribunal's decision. When inconsistent decisions arise, FDI is again seen as risky, as unpredictable decisions can bring high costs to both investors and states. Investment treaties were created to promote FDI by providing protection to foreign investment and reducing risk; but inconsistent decisions prevent this purpose from effectuating, making investment treaties less protective of foreign investment, and provide no direction for states to conform regulatory actions in the future. (Howard, 2017, p. 27)

\subsection{Argumento que contrarresta el argumento en contra de la despolitización}

Hemos visto ya el argumento que proclamaba la despolitización como una de las ventajas del arbitraje-hoc sobre mecanismos que suponen desde una mayor intervención hasta el control absoluto de los Estados sobre el nombramiento de los miembros de las instancias encargadas de resolver las controversias entre los inversionistas y dichos Estados.

Desde la otra orilla, dicho mayor protagonismo estatal constituye más bien una de las ventajas que aportaría el descarte del arbitraje ad hoc en favor de mecanismos que se acerquen a instancias cuasi-jurisdiccionales, tales como un tribunal de apelaciones o una corte multilateral permanente. 
Un argumento importante en el que se apoya esta postura a favor de la reforma es que considera artificial el argumento de que el arbitraje ad hoc logra neutralizar el elemento político y aleja al conjunto de las controversias inversionista-Estado de los juegos de poder de la política internacional, acercándola más bien al laboratorio técnico-jurídico y aséptico del arbitraje.

Sin duda, resulta plausible que la canalización hacia el arbitraje de controversias en las que Estados soberanos son parte constituya un desincentivo para el escalamiento de presiones políticas alrededor de la controversia.

Sin embargo, hay que tener cuidado en no sobredimensionar las consecuencias de esa plausible correlación. No cabe duda que las controversias inversionista-Estado manifiestan un nivel de interés variable en lo que se refiere a los intereses políticos de los Estados. Ahora bien, si el nivel de interés político en un determinado caso llega a ser lo suficientemente significativo como para justificar la intervención o involucramiento del Estado, actor principal en el ámbito de las relaciones internacionales, interesará muy poco que la referida controversia haya sido encausada previamente o pretenda encausarse por el carril del arbitraje internacional.

Dicha conclusión es concordante con análisis ya tradicionales en el derecho internacional público que contextualizan las controversias jurídicas dentro del sistema de las relaciones internacionales. En este sentido, José Antonio Pastor Ridruejo (2014) nos señala el camino de que la distinción relevante no está entre el ámbito político y el ámbito jurídico, sino en la diferenciación entre aquellos temas más proclives al cumplimiento y aquellos en los que dichos compromisos resultan más complicados, independientemente del medio de solución de controversias que se utilice:

Y se desconoce sobre todo el hecho de que en ciertos sectores de la convivencia internacional — los que afectan a la coexistencia, reciprocidad y cooperación — el Derecho Internacional alcanza niveles de observancia y acatamiento muy considerables. Así, lo normal y cotidiano es que se respete la soberanía territorial de los Estados, que se cumplan las normas sobre misiones y agentes diplomáticos, que se observen los tratados. Otra cosa ocurre, sin embargo, cuando los intereses en juego entre los Estados son altamente políticos. En estos casos no puede hablarse de una observancia mínimamente satisfactoria del Derecho Internacional. (pp. 26-27)

Conforme a este marco, la esperanza de que el arbitraje logre neutralizar una pretendida contaminación política encapsulando el problema dentro de un aislamiento jurídico que haga más sencillo resolver la controversia resultaría, al menos, ingenua.

Dicha esperanza sería, más bien, un espejismo o una mera declaración de propósitos que, tarde o temprano, se toparía con los presupuestos políticos que explican las acciones de los Estados. Pretendiendo escapar de la realidad política, la ficción 
jurídica tendrá al final más bien que reconocer la sustancia política subyacente que determina los límites del derecho internacional.

Adicionalmente, un elemento de contexto histórico seguramente alimentaba dicho argumento en favor del arbitraje ad hoc y la pretendida neutralización de la variable política.

En efecto, dicho papel políticamente neutralizador del arbitraje en controversias que involucran a Estados resulta más propio del contexto de la década de los sesenta que corresponde a los años de creación del CIADI, al proceso de descolonización en África y Asia y al auge del movimiento de los países del Sur en pos de un nuevo orden económico internacional. La realidad del contexto actual es distinta, por lo que dicho pretendido papel del arbitraje debería reevaluarse.

Un argumento menos sesudo y más empírico, pero que va en la misma línea de razonamiento, se apresuraría en recordar que no es exacta la correlación entre intervención política de los Estados y afectación de intereses económicos de agentes económicos particulares nacionales.

En las últimas dos décadas se ha visto que los Estados más desarrollados y económicamente poderosos se han visto demandados de manera creciente en arbitrajes de inversión. Esto ha conllevado a que dichos Estados generalmente exportadores netos de capitales hayan sido muy cautelosos y hasta reacios a apoyar a sus inversionistas en procedimientos arbitrales ya que dichos procesos podrían culminar en decisiones que consagren interpretaciones que, posteriormente, se podrían volver en contra de ellos mismos al ver comprometidos sus intereses defensivos en otros procesos arbitrales.

\subsection{Argumento en contra del peligro de captura por parte de los países más poderosos, con particular referencia a la OMC}

En la sección precedente relativa a los argumentos en contra del tribunal de apelaciones y corte multilateral de inversiones hemos visto que uno de estos razonamientos, estrechamente relacionado con aquel que advierte del peligro de la politización extendida, radica en señalar la posibilidad de que el mayor protagonismo de los Estados en la conformación de estas nuevas instancias de decisión podría desembocar en la captura de estas instancias por los Estados más poderosos.

La argumentación que le sale al frente a dicha pretendida alerta minimiza el riesgo de captura seńalando que el asunto justamente recaería en negociaciones a cargo de los propios Estados. Cada uno de ellos entonces tendría la decisión de acompañar o no los consensos que se irían formando. Con seguridad la forma en que se llevarían adelante estas negociaciones permitiría a los Estados ir monitoreando los resultados parciales de las negociaciones e irlos calibrando a fin de apoyar o no el resultado final. 
Después de todo no se puede pensar que existe un determinismo a priori que condene a los Estados en vías de desarrollo a arribar a o aceptar resultados que les sean adversos. Entre otros, el propio estancamiento actual de las negociaciones en el marco de la OMC constituye evidencia empírica de que los intereses de los países en desarrollo también se reflejan en los resultados políticos de la escena internacional.

Otro punto relacionado que aconsejaría la adopción de una postura audaz en este punto por parte de los Estados en supuesta desventaja política es que, dado que no existe una evidencia concluyente sobre la correlación entre el arbitraje ad hoc y la atracción de capitales, la apuesta de poner en riesgo al referido arbitraje ad hoc no conllevaría necesariamente la afectación del prospecto de atracción de inversión extranjera.

\subsection{Incompatibilidad con CIADI}

Hemos visto líneas arriba cómo uno de los argumentos en contra del descarte del arbitraje como medio de solución de controversias inversionista-Estado es su engarce y compatibilidad con el sistema CIADI que fue diseñado justamente en torno al arbitraje y su naturaleza ad hoc.

La primera línea de respuesta a ese argumento en realidad simplemente señala que un tribunal de apelaciones o una corte multilateral no presentan necesariamente incompatibilidad con la arquitectura CIADI.

La prueba estaría en la práctica estatal de la Unión Europea que ha incluido un tribunal de primera instancia y un tribunal permanente de apelaciones como segunda instancia en sus acuerdos de inversión o tratados de libre comercio relativamente recientes, tales como con Canadá y Vietnam. En estos acuerdos se llega incluso a decir que la Secretaría del CIADI administrará y se constituirá en la secretaría del tribunal de primera instancia.

Más específicamente, dicha pretendida compatibilidad radicaría en la declaración incluida en dichos acuerdos de la UE con Canadá y Vietnam en la que las partes acuerdan que los laudos emitidos por los tribunales son ejecutables de conformidad con el Convenio CIADI.

Los artículos 8.41(6) del acuerdo de la UE con Canadá y 3.57(8) del acuerdo UE-Vietnam contienen dichas declaraciones. Así, por ejemplo, reza el artículo 3.57(8) del acuerdo con Vietnam:

For greater certainty and subject to subparagraph 1 (b), where a claim has been submitted to dispute settlement pursuant to subparagrapch 2(a) of Article 3.33 (Submission of a Claim), a final award issued pursuant to this Section shall qualify as an award under Section 6 of Chapter IV of the ICSID Convention. 
Esta salida de la UE pretende superar el obstáculo del artículo 53(1) del Convenio CIADI recurriendo a la posibilidad de modificar tratados inter se prevista por el artículo 41.1 de la Convención de Viena sobre Derecho de los Tratados de 1969:

41. Acuerdos para modificar tratados multilaterales entre algunas de las partes únicamente. 1. Dos o más partes en un tratado multilateral podrán celebrar un acuerdo que tenga por objeto modificar el tratado únicamente en sus relaciones mutuas:

a) si la posibilidad de tal modificación está prevista por el tratado; o

b) si tal modificación no está prohibida por el tratado, a condición de que:

i) no afecte al disfrute de los derechos que a las demás partes correspondan en virtud del tratado ni al cumplimiento de sus obligaciones; $y$

ii) no se refiera a ninguna disposición cuya modificación sea incompatible con la consecución efectiva del objeto y del fin del tratado en su conjunto.

Desde el punto de vista estrictamente jurídico resulta cuestionable que la solución subjetiva prevista en torno a la declaración de compatibilidad interpartes logre en estricto superar la valla objetiva impuesta por los artículos 26 y 53 del Convenio CIADI.

Sin embargo, el argumento en favor de los tribunales de apelación o corte internacional recuerda que son los propios Estados gestores y obligados por dichos tratados los finalmente llamados a ejecutar en sus respectivos territorios las obligaciones asumidas internacionalmente. En esta lógica poco importaría de que el cumplimiento de dicha obligación derive o no de la materialización del supuesto previsto en la Convención de Viena.

Lo importante para esta visión es que existe un compromiso internacional de dar la fuerza de sentencias nacionales de máxima instancia a los laudos emitidos por estos tribunales arbitrales de primera instancia y de apelaciones y que son estos los Estados llamados finalmente a aplicar estos laudos en sus territorios.

Adicionalmente, debe subrayarse que la versión maximalista de esta posición que aboga por tribunales de apelaciones o cortes de inversión no tiene problemas en señalar que su propuesta no depende ni requiere de esta compatibilidad y convergencia con el sistema CIADI y sus mecanismos de ejecución de laudos. Esta posición señala que dichos tribunales pueden perfectamente funcionar como un sistema independiente y autocontenido de adjudicación internacional, apoyándose en sus propios mecanismos de ejecución.

¿Qué hay de la aplicación de la Convención de Nueva York de 1958 a estos laudos ajenos al sistema CIADI? 
Esta variable relativa a la aplicabilidad del Convenio CIADI es de interés particularmente respecto a la posibilidad de ejecutar estos laudos extraños al sistema CIADI en territorios distintos a los países que sí formarían parte del aludido sistema de tribunales de apelaciones o corte multilateral.

¿Tendrían estos laudos extra-CIADI el manto protector de la Convención de Nueva York?

La respuesta debe repetir el análisis del artículo 1 de la Convención de Nueva York ya efectuado líneas arriba.

Sin embargo, la postura que aboga por el tribunal de apelaciones o corte multilateral contradice dicha conclusión señalando que es aún una cuestión debatible si las decisiones que emitirían estas nuevas instancias estarían incluidas dentro del concepto de «sentencia arbitral» del artículo 1 de la Convención de Nueva York.

Adicionalmente apunta que, dado que la aplicabilidad de la Convención de Nueva York residirá finalmente en las decisiones de cortes nacionales en cada caso concreto, el factor determinante sobre dicha aplicabilidad residirá en gran parte en el número de países que se sumen a la iniciativa de instaurar un tribunal de apelaciones o una corte multilateral. En la medida en que dicha iniciativa genere mayor número de adeptos, mayor será seguramente el número de cortes y, eventualmente, el conjunto de países que optarían por la aplicación benevolente de la Convención de Nueva York.

Esas mismas voces se apresuran a anotar que, por último, la cuestión de la aplicabilidad de la Convención de Nueva York a los laudos a ser emitidos por las nuevas instancias o instancia que se quiere crear resulta marginal. Ello debido a que en la práctica los casos de ejecución de laudos en materia de inversiones en territorios distintos al Estado parte de la controversia resultan notoriamente escasos.

\subsection{La necesidad de un mecanismo que acerque las decisiones del sistema al ideal de exactitud y corrección de todo sistema de justicia}

Alcanzar decisiones correctas es un objetivo primordial para todo sistema de administración de justicia. En esa línea, todo mecanismo que razonablemente permita avanzar hacia la consecución, así sea gradual y parcial, de dicho objetivo, debería ser considerado favorablemente por dicho sistema.

He ahí la premisa fundamental en la que se funda esta crítica en contra del sistema actual de arbitraje ad hoc en la solución de controversias inversionista-Estado.

Desde sus inicios, el movimiento que persigue la reforma del arbitraje ad hoc inversionista-Estado ha asignado un rol preponderante al objetivo de alcanzar un mayor nivel de exactitud y corrección en los laudos o decisiones. Para alcanzar el nivel 
ideal de exactitud y corrección este movimiento considera imprescindible eliminar la naturaleza ad hoc del sistema actual de arbitraje inversionista-Estado.

La propuesta respecto a la necesidad y urgencia de que el sistema busque asegurar mayores niveles de corrección se ha visto reforzada por la evidencia empírica encontrada respecto al récord del sistema actual de arbitraje ad hoc respecto a la repetición de los errores que se presentan en los laudos y a la insuficiencia e inefectividad de mecanismos (tales como las declaraciones interpretativas) que permitan a los Estados intervenir a fin de corregir y prevenir esos errores.

Así por ejemplo, un reciente estudio del profesor Alschner revisa la práctica arbitral relevante y llega a la conclusión que las decisiones catalogadas como erróneas por el consenso prevaleciente o que han sido anuladas o cuya ejecución ha sido rechazada, no son realmente descartadas por el sistema ad hoc. También encuentra que las interpretaciones autoritativas de los tratados por parte de los Estados parte no son tomadas en cuenta y, en general, no existe evidencia de que los tribunales arbitrales converjan hacia una jurisprudence constante.

En esa línea citamos las conclusiones de Alschner (2019):

The article finds that annulled or set-aside decisiosn continue to be cited by later tribunals, that contracting states' authoritative interpretations are disregarded, and that subsequent tribunals do not generally converge around a jurisprudence constante. As a result, "wrong" awards don't die in ISDS, instead past arbitral "mistakes" are repeated and continue to shape the development of investment law. More explicit shepardization of awards, tighter rules on what counts as precedent or broader institutional reform are posible solutions to improve the prospective effect of correctness determinations. (p. 3)

Resumiendo, conforme a esta perspectiva el sistema ad hoc de arbitraje inversionistaEstado ha sido y sigue siendo un terreno fértil para perpetuar la presencia de decisiones manifiestamente incorrectas. Esta situación clama por la incorporación de mecanismos que aseguren al menos la pretensión del ideal de arribar a un mayor nivel de exactitud y corrección.

\subsection{Costos y duración}

Existe una visión contraria al argumento que respalda la estimación de que una instancia procesal adicional del sistema traería necesariamente un costo mayor tanto por la vía directa de los costos de instalación y mantenimiento de la instancia, como por la vía indirecta de la mayor duración y gastos relacionados a la dilatación de los procesos. 
La tesis a favor de las instancias de revisión responde que los costos derivados de la implementación y manutención de los mecanismos de apelación o corte multilateral se verán más que compensados por múltiples ahorros resultantes por varias vías.

Una de esas vías es la eliminación de la instancia de anulación o no reconocimiento que existe actualmente ante el CIADI y cortes nacionales, respectivamente. Adicionalmente, no cabe duda que estas instancias han sido ampliamente utilizadas como un intento de infiltrar argumentos que en puridad corresponden a una apelación, pero que han pretendido forzar el molde restringido de las causales de anulación o de denegación de reconocimiento y ejecución.

Adicionalmente, la posición de los que apoyan la formación de una corte multilateral o una instancia de apelaciones afirman que en dicho cálculo debería incluirse el ahorro prospectivo que representaría para los Estados la disminución de demandas frívolas por parte de los inversionistas y, principalmente, el impacto en el pago de indemnizaciones millonarias que se alimentan de la falta de coherencia y uniformidad que exhibe el sistema arbitral $a d$ hoc.

Es muy difícil que un estudio estadístico permita arribar a una conclusión definitiva sobre esta discusión en materia de costos, por lo que este debate continuará sin duda abierto.

Sin embargo, cabe realizar una importante atingencia adicional y es que incluso si una instancia de apelaciones o una corte determinaran mayores costos que el mantenimiento del sistema ad hoc actual, definitivamente el precio no es la única variable que toma en cuenta un Estado eficiente en la determinación del gasto.

Como ejemplo basta recordar que la ley peruana 30225, Ley de Contrataciones del Estado, incluye dentro de sus principios a la eficacia y eficiencia que determinan el mejor uso de los recursos públicos 5 .

En este orden de ideas, en la medida que una instancia de apelaciones o una corte multilateral aporten los beneficios que prometen, los Estados podrían legítimamente decidir que la asunción de ese mayor costo, de configurarse realmente, bien vale la pena.

\footnotetext{
5 Los gastos del Estado peruano derivados de su participación en los arbitrajes de inversión se encuentran excluidos del ámbito de la Ley de Contrataciones del Estado (ley 30225). Sin embargo, la referencia a los principios básicos que informan las decisiones de adquisición de bienes y servicios del Estado que se encuentran en dicha Ley resulta pertinente. Entre ellos se encuentra el Principio de Eficacia y Eficiencia el cual siempre debería informar las decisiones de gasto en materia de contratación pública, así no resulte aplicable la referida Ley de Contrataciones. El inciso f) del artículo 2 desarrolla el referido Principio de Eficacia y Eficiencia: el proceso de contratación y las decisiones que se adopten en su ejecución deben orientarse al cumplimiento de los fines, metas y objetivos de la Entidad, priorizando estos sobre la realización de formalidades no esenciales, garantizando la efectiva y oportuna satisfacción de los fines públicos para que tengan una repercusión positiva en las condiciones de vida de las personas, así como del interés público, bajo condiciones de calidad y con el mejor uso de los recursos públicos».
} 


\subsection{Sesgo y conflictos de interés de los árbitros (double-hatting)}

Esta crítica se basa en la denuncia de la dualidad en la actividad de los árbitros que desempeñan funciones de árbitros en algunos casos, mientras en otros casos y las más de las veces paralelamente, son abogados de parte defendiendo intereses de inversionistas.

La fuente de este potencial conflicto de intereses puede ser extremadamente diversa. Incluye, por ejemplo, situaciones en que estos árbitros al actuar también en la práctica privada pueden verse enfrentados a decidir como árbitros casos en los que se ventilan situaciones similares a las que enfrentan en otros casos y entre otras partes sus defendidos, empresas vinculadas a sus defendidos o incluso empresas en las que estos mismos árbitros-abogados ejercen como directores o funcionarios.

Citaremos en esta materia una voz tan autorizada como la del juez Thomas Buergenthal que ya en el año 2006 afirmaba que dicha yuxtaposición de intereses atentaba contra su entendimiento del debido proceso:

I have long believed that the practice of allowing arbitrators to serve as counsel, and counsel to serve as arbitrators, raises due process of law issues. In my view, arbitrators and counsel should be required to decide to be one or the other, and be held to the choice they have made, at least for a specific period of time. That is necessary, in my opinion, in order to ensure that an arbitrator will not be tempted, consciously or unconsciously, to seek to obtain a result in an arbitral decision that might advance the interests of a client in a case he or she is handling as counsel. ICSID is particularly vulnerable to this problem because the interpretation and application of the same or similar legal instruments - the Bilateral Investment Treaties, for example - are regularly at issue in different cases before it.

[...]

These revolving-door problems counsel selecting an arbitrator who, the next time around when the arbitrator is counsel, selects the previous counsel as arbitrator should be avoided. Manus manum lavat, in other words - you scratch my back and I'll scratch yours, does not advance the rule of law. (Citado en Bernasconi-Osterwalder, Johnson y Marshall, 2011, pp. 3-4)

La propuesta que favorece una instancia de apelaciones o una corte multilateral postula la eliminación de este rasgo problemático y generador de suspicacias del arbitraje ad hoc y su sustitución por un mecanismo de carácter permanente compuesto por miembros con un estatus análogo al de la vocación de permanencia y dedicación exclusiva que caracteriza a los jueces en sede nacional.

Por lo expuesto, el argumento de esta tesis adquiere mayor fuerza y prácticamente se identifica con la versión de las instancias de apelación o corte permanente que incluyen miembros o jueces que sirven por un período más o menos extendido y a dedicación exclusiva. 
Esta es una propuesta, por tanto, que apuesta por el camino de la cuasi-judicialización del sistema de controversias inversionista-Estado.

\subsection{Interés público}

Para nadie es una novedad constatar que los temas que regularmente caen bajo la esfera de decisión de los árbitros y tribunales internacionales de inversión trascienden la esfera privada y caen de lleno en temas de interés público, a veces fundamentales. En ese sentido, afirma el profesor Van Harten (2013):

Investor-state arbitration offers a unique context in which to study adjudicator behaviour. Exceptionally, it is a context in which asymmetrical arbitration is used to resolve core issues arising from the relationship between the state, in its regulatory capacity, and private parties. Both investment treaty arbitration and, on a qualified basis, investment contract arbitration are forms of regulatory adjudication in that they are used to delineate sovereign authority. (pp. 6-7)

A partir de esta realidad que describe una tensión entre el método arbitral y la potestad regulatoria estatal, esta crítica duda de la idoneidad de poner en manos de un sistema de adjudicación asimétrico ${ }^{6}$ en favor del inversionista o, en el mejor de los casos tan riesgosamente contingente, cuestiones esenciales relativas al interés público y potencialmente limitantes de atribuciones soberanas y legítimas de los Estados.

Habría entonces un desbalance inherente entre la calidad y trascendencia de la materia sustancial puesta bajo la competencia de estos tribunales arbitrales, por un lado, y, por el otro, su naturaleza ad hoc y falta de certeza respecto a su performance.

¿No habría ido demasiado lejos, entonces, el arbitraje ad hoc al desbalancear un delicado balance que debería tener una mayor deferencia al interés público? En este sentido resulta apropiado citar la reflexión de Gabrielle Kaufmann-Kohler (2011), reconocida árbitro internacional, por lo que su opinión no puede ser objetada como sesgada en favor de los Estados:

Algunos creen que el arbitraje no es apropiado para resolver disputas de inversión, o que la resolución de controversias de inversión se encuentra en un estado de transición entre el arbitraje comercial internacional y una forma de control cuasi judicial internacional de la conducta regulatoria de los Estados que aún se encuentra en desarrollo [...].

\footnotetext{
6 Esta asimetría se puede asociar, por supuesto, a la idea de que el arbitraje de inversiones es un mecanismo cuyas reglas favorecen al inversionista, toda vez que por ejemplo en el caso del arbitraje por tratado solo los privados pueden ser demandantes y el sesgo pro-inversionista que podría acarrear la naturaleza ad hoc del arbitraje. Sin embargo, más allá de esa toma de posición, un elemento más objetivo que no se puede negar es que existe una asimetría por la correlación de intereses en juego. Mientras el consentimiento del inversionista se agota en su realidad particular, el consentimiento del Estado arrastra el interés colectivo de toda la población que forma parte de él.
} 
La cuestión inmediata en la práctica es entonces cómo reconciliar la naturaleza pública de las disputas de inversión con la naturaleza tradicionalmente privada del arbitraje. Puesto de otra forma, la pregunta es cómo dar cabida al componente de interés público en el arbitraje de inversión. (p. 136)

Desde tal punto de vista resultaría lógico que los Estados Parte del sistema, busquen retomar o, al menos, ganar mayor control sobre el mecanismo de solución de controversias que ellos mismos instauraron décadas atrás. Después de todo fueron ellos mismos quienes consagraron la aplicación del arbitraje inversionista-Estado y conforme al viejo adagio «los Estados son los amos de sus tratados».

El principal móvil detrás de dicha postura sería precisamente llevar al interés público al lugar preponderante que le debería corresponder en las consideraciones que deben arbitrar controversias que lo contraponen a intereses privados.

En esa línea, se puede afirmar que los Estados habrían evaluado la necesidad de reequilibrar, por la vía de un mecanismo procesal menos proclive al desbocamiento o incluso más cercano a sus intereses, una serie de privilegios de los que goza el sistema arbitral ad hoc desde su concepción. Entre estos privilegios podríamos contar importantes excepciones a la aplicación de principios generales consagrados en materia de derecho internacional público y principios de derecho societario (Gaukrodger, 2014, p. 7), tales como, respectivamente, el agotamiento de recursos internos (que, en principio, no admite excepciones ni en materia de protección de derechos humanos fundamentales, salvo en caso de futilidad) y la no admisión de reclamaciones a título personal de accionistas por daños sufridos por la sociedad misma (CIJ, 1970).

\section{Conclusiones}

El debate relativo a un mecanismo de apelaciones y una corte multilateral de inversiones resulta probablemente el más importante en la actualidad para el derecho internacional de las inversiones. Con seguridad constituye el que más impacto podría tener sobre dicho régimen, al desafiar la idoneidad de su naturaleza ad hoc actual, característica esencial desde su concepción hace más de cinco décadas.

Es claro, por la propia agenda de trabajo del Grupo de Trabajo III de UNCITRAL sobre la reforma del sistema de solución de controversias inversionista-Estado, que existen otros temas a propósito de la reforma, como la duración y los costos de los procedimientos y el mecanismo de nombramiento de árbitros que resultan importantes y que por ello, son parte de las negociaciones multilaterales en curso.

Sin embargo, no cabe duda que el protagonismo en ese debate recae sobre la cuestión de la falta de consistencia y coherencia en las decisiones del sistema ad hoc. Ello le 
transmite centralidad a las propuestas de un mecanismo de apelaciones y de una corte multilateral porque estas tocan directamente el punto neurálgico respecto a la necesidad de un mecanismo de revisión para hacer frente a las carencias que son las que preferentemente ha denunciado la crítica como la fuente de la falta de legitimidad del sistema actual.

El interés que concita la propuesta de la corte multilateral se entiende también por el trascendental impacto que podría tener sobre el arbitraje ad hoc que tradicionalmente ha acompañado al derecho internacional de las inversiones, pudiendo llegar incluso a sustituirlo.

A contrapie de la importancia sistémica del resultado de las negociaciones en curso sobre la reforma del mecanismo de solución de controversias inversionista-Estado, de la atención que el tema ha concitado y sigue concitando internacionalmente, y del hecho que el Perú hace poco regresó como miembro pleno de UNCITRAL, el debate sobre la cuestión ha brillado por su ausencia en nuestro país.

Ello resulta especialmente problemático porque no se trata únicamente de definir la postura del Estado peruano en lo que respecta a un mecanismo de solución de controversias que ha estado en las primeras planas últimamente a propósito de casos que involucran temas muy sensibles de corrupción, sino que dicho sistema se encuentra estructuralmente ligado a definiciones de interés público que resultan esenciales para delimitar el espacio regulatorio que se desprende necesariamente de la soberanía del Estado y de su obligación de gobernar.

A dicha consideración de carácter estructural debemos añadir otra de orden eminentemente práctico y de aplicación particular al caso peruano. Independientemente de la posición que asuma el Perú en las negociaciones en el marco de UNCITRAL, no es secreto para nadie que el peso específico de la economía peruana limita fuertemente el impacto sistémico que dicha posición pueda tener en el resultado final de las negociaciones multilaterales.

Sin embargo, debe tomarse en cuenta que, dado el nivel de inflexibilidad y escaso margen de negociación que han evidenciado los dos polos extremos en la negociación en el seno del Grupo de Trabajo III de UNCITRAL, es decir, los Estados Unidos y la Unión Europea, resulta probable que esta dinámica cismática determine una fragmentación del sistema de solución de controversias inversionista-Estado. En dicho escenario, tendrían que coexisitir (y competir) un conjunto de acuerdos siguiendo el modelo estadounidense que replique o continúe en la senda del arbitraje ad hoc y otro grupo, opuesto, plegado a la propuesta de la Unión Europea en torno a una corte multilateral de inversiones. 
Frente a esta posibilidad, el Perú deberá necesariamente enfrentar el dilema de negociar o no bajo el esquema de la corte en caso persiga concretar un acuerdo de inversiones con la UE (recordemos que el tratado de libre comercio vigente entre ambos no contiene un capítulo en materia de inversiones). Cabe resaltar que el Perú también deberá enfrentar dicha encrucijada en caso sea la Unión Europea quien pretenda dejar de lado los acuerdos bilaterales de inversión que muchos de sus Estados miembros mantienen con el Perú. Esta última hipótesis es más que plausible porque siendo la UE la abanderada de una corte multilateral, difícilmente quiera enfrentar la contradicción de abogar por esta propuesta mientras mantiene acuerdos de primera generación que se caracterizan por su remisión al arbitraje ad hoc. La importancia para el Perú de cómo se decantará este tema es sustancial, si tenemos en cuenta que los principales inversionistas europeos en territorio peruano se encuentran bajo el ámbito de aplicación de estos acuerdos de primera generación y que estos acuerdos son precisamente aquellos que responden al modelo que ha sido denunciado como peligroso para los intereses defensivos de los Estados por su notoria vaguedad y ambivalencia.

Hemos visto en una extensa sección de este artículo que existen argumentos para defender la flexibilidad que brinda la naturaleza ad hoc del arbitraje de inversiones tal como existe actualmente. También hemos pasado revista a una serie de argumentos que sostienen la conveniencia de rediseñar el sistema en busca de la legitimidad que parece ya no tener el sistema actual, porque el riesgo de decisiones contradictorias y el riesgo de la falta de certeza y coherencia que son inherentes al carácter ad hoc del arbitraje ya no coincide con el equilibrio de las fuerzas políticas subyacentes a la que la juridicidad del sistema debe rendir cuentas.

Un argumento poderoso que muy bien podría terminar inclinando el fiel de la balanza hacia la consideración de la conveniencia de una instancia de apelaciones o una corte multilateral viene por el lado de asignar preeminencia a la variable del interés público. En esta visión de las cosas, el interés público es una razón suficiente para buscar una modificación sustancial del sistema tal y como existe hoy en día. El hecho que se ponga en riesgo, a través de un sistema de decisiones contingentes, el interés público y la delimitación de los márgenes adecuados que deben acompañar la actividad gubernamental persiguiendo dicho interés público, parecería que en la actualidad ya no pasa el filtro de la legitimidad política. Ello habría impactado en un nuevo análisis costo-beneficio realizado por la comunidad internacional y que determinaría la prescindencia del arbitraje ad hoc, máxime si la evidencia empírica respecto a su promesa de atracción de inversión extranjera no resulta concluyente.

Siguiendo dicha línea de razonamiento, cabe preguntarse si los días del modelo del arbitraje ad hoc como mecanismo estrella de solución de controversias entre inver- 
sionistas y Estados ya han corrido su curso. Existe evidencia en este sentido tan cercana como el proceso de negociación entre la Alianza del Pacífico y los candidatos a Estados Asociados donde al parecer el consenso se encuentra más cercano a no incluir un mecanismo de solución de controversias inversionista-Estado.

Finalmente, la respuesta que se le otorgue a dicha pregunta desde el lado peruano tendrá un impacto que, sin duda, excederá el ámbito del arbitraje internacional y del derecho internacional de las inversiones. Con toda seguridad dicha conclusión tendrá repercusiones determinantes en cuestiones tan significativas como el debate relativo al equilibrio entre el interés público y el interés privado que enfrenta el Estado recurrentemente en sus decisiones y diseño de políticas y solución de controversias en general, así como en la discusión tan actual respecto al estándar de motivación requerido en la anulación de laudos arbitrales.

\section{Referencias bibliográficas}

Alschner, W. (2019). Correctness of Investment Awards: Why Wrong Decisions Don't Die. Forthcoming, The Law and Practice of International Courts and Tribunals. SSRN. Recuperado de https://papers.ssrn.com/sol3/papers.cfm?abstract_id=3429397

Álvarez, J. M. (2018). Legitimacy Concerns of the Proposed Multilateral Investment Court: Is Democracy Possible? Boston College Law Review, 59(8), 2765-2790.

CIJ - Corte Internacional de Justicia. (1970). Caso Relativo a la Barcelona Traction, Light and Power Company, Limited. Recuperado de https://legal.un.org/docs/?path=../ icjsummaries/documents/spanish/st_leg_serf1.pdf

Bernasconi-Osterwalder, N., Johnson L. y Marshall, F. (2011). Arbitrator Independence and Impartiality: Examining the dual role of arbitrator and counsel. Background Papers IV Annual Forum for Developing Country Investment Negotiators New Delhi 27-29 October 2010. Winnipeg: International Institute for Sustainable Development.

Bottini, G. (2015). Reform of the Investor-State Arbitration Regime: The Appeal Proposal. En J. Kalicki y A. Joubin-Bret (eds.), Reshaping the Investor-State Dispute Settlement System (pp. 455-473). Leiden: Nijhoff-Brill.

Gaukrodger, D. (2014). Investment Treaties and Shareholder Claims for Reflective Loss: Insights from Advanced Systems of Corporate Law. París: OECD Working Papers on International Investment Law.

González García, L. (2015). Making Impossible Investor-State Reform Possible. En J. Kalicki y A. Joubin-Bret (eds.), Reshaping the Investor-State Dispute Settlement System (pp. 424-436). Leiden: Nijhoff-Brill.

Mankiw, N.G. (2012). Principios de Economía. México D.F.: Cengage Learning.

Holtzmann, H. (1995). A Task for the 21st Century: Creating a New International Court for Resolving Disputes on the Enforceability of Arbitral Awards. En M. Hunter et al. (eds.), The Internationalisation of International Arbitration: The LCIA Centenary Conference (pp. 109-115). Londres: Graham and Trotman/Martinus Nijhoff. 
Howard, D.M. (2017). Creating Consistency Through a World Investment Court. Fordham International Law Journal, 41(1). Recuperado de https://ir.lawnet.fordham.edu/cgi/ viewcontent.cgi? article $=2685 \&$ context $=\mathrm{ilj}$

Johnson, L. (2012). The 2012 US Model BIT and What the Changes (Or Lack Thereof) Suggest about Future Investment Treaties. Political Insurance Newsletter, 8(2), 1-5. Recuperado de http://ccsi.columbia.edu/files/2014/01/johnson_2012usmodelBIT.pdf

Kaufmann-Kohler, G. (2011). La anulación de los laudos arbitrales del CIADI en arbitrajes de contratos y tratados: ¡existen diferencias? Anuario Latinoamericano de Arbitraje. "Sistema de Anulación de los Laudos CIADI", 1(1), 121-140.

Knull III, W.H. y Rubins, N.D. (2000). Betting the Farm on International Arbitration: Is it Time to Offer an Appeal Option? American Revue of International Arbitration, 11(4), 536-564.

Legum, B. (2015). Appellate Mechanisms for Investment Arbitration: Worth a Second Look for the Trans-Pacific Partnership and the Proposed EU-US FTA? En J. Kalicki y A. Joubin-Bret (eds.), Reshaping the Investor-State Dispute Settlement System (pp. 437-442). Leiden: Nijhoff-Brill.

Lowenfeld, A. (2009). The ICSID Convention: Origins and Transformation. Georgia Journal of International and Comparative Law, 38(1), 47-61.

Tribunal de Justicia de la Unión Europea. (30 de abril de 2019). Opinión 1/17.

Pastor Ridruejo, J. A. (2014). Curso de Derecho Internacional Público y Organizaciones Internacionales. Madrid: Tecnos.

Paulsson, J. (2014). Preface. En W. Mattli y T. Dietz, International Arbitration \& Global Governance. Contending Theories and Evidence. Oxford: Oxford University Press.

Schwebel, S.M. (1995). The Creation and Operation of an International Court of Arbitration Awards. En M. Hunter, A. Marriott y V. V. Veeder (eds.), The Internationalisation of International Arbitration: The LCIA Centenary Conference (pp. 109-115). Londres: Graham and Trotman/Martinus Nijhoff.

UNCITRAL. (2017). Informe de la Comisión de Naciones Unidas para el Derecho Mercantil Internacional. $50^{\circ}$ Período de Sesiones A/72/17. Viena.

Van Harten, G. (2013). Sovereign Choices and Sovereign Constraints. Judicial Restraint in Investment Treaty Arbitration. Oxford: Oxford University Press.

Vandevelde, K. (2009). A Brief History of International Investment Agreements. University of California at Davis Journal of International Law and Policy, 12(1), 157-194.

Recibido: 1 de abril de 2020 Aprobado: 17 de julio de 2020 